\title{
Chapter 6 Quantifying Tree Biomass Carbon Stocks and Fluxes in Agricultural Landscapes
}

\author{
Shem Kuyah, Cheikh Mbow, Gudeta W. Sileshi, Meine van Noordwijk, \\ Katherine L. Tully, and Todd S. Rosenstock
}

\begin{abstract}
This chapter presents methods to quantify carbon stocks and carbon stock changes in biomass of trees in agricultural landscapes. Specifically it assesses approaches for their applicability to smallholder farms and other tree enterprises in agricultural landscapes. Measurement techniques are evaluated across three criteria: accuracy, cost, and scale. We then recommend techniques appropriate for users looking to quantify carbon in tree biomass at the whole-farm and landscape scales. A basic understanding of the carbon cycle and the concepts of biomass assessment is assumed.
\end{abstract}

\subsection{Introduction}

Trees and woody biomass play an important role in the global carbon cycle. Forest biomass accounts for over $45 \%$ of terrestrial carbon stocks, with approximately $70 \%$ and $30 \%$ contained within the above and belowground biomass, respectively (Cairns et al. 1997; Mokany et al. 2006). Not all trees exist inside forests, however.

\footnotetext{
S. Kuyah $(\square)$

World Agroforestry Centre (ICRAF), UN Avenue-Gigiri, PO Box 30677-00100,

Nairobi, Kenya

Jomo Kenyatta University of Agriculture and Technology (JKUAT),

Nairobi, Kenya

e-mail: s.kuyah@cgiar.org

C. Mbow • T.S. Rosenstock

World Agroforestry Centre (ICRAF), UN Avenue-Gigiri, PO Box 30677-00100,

Nairobi, Kenya

G.W. Sileshi

Freelance Consultant, 5600 Lukanga Road, Kalundu, Lusaka, Zambia

M. van Noordwijk

World Agroforestry Centre (ICRAF), Bogor, Indonesia

K.L. Tully

University of Maryland, College Park, MD, USA

(C) The Editor(s) (if applicable) and the Author(s) 2016

T.S. Rosenstock et al. (eds.), Methods for Measuring Greenhouse Gas Balances and Evaluating Mitigation Options in Smallholder Agriculture,

DOI 10.1007/978-3-319-29794-1_6
} 
Table 6.1 Typical precision for various quantification uses

\begin{tabular}{l|l|l}
\hline End user & Potential uses & Typical precision \\
\hline National governments & Reporting to the IPCC & Variable \\
\cline { 2 - 3 } & $\begin{array}{l}\text { Development of National Appropriate } \\
\text { Mitigation Actions }\end{array}$ & \pm 10 to $20 \%$ \\
\hline Markets & $\begin{array}{l}\text { Carbon trading between governments and } \\
\text { businesses }\end{array}$ & Undefined \\
\hline $\begin{array}{l}\text { Development } \\
\text { organizations }\end{array}$ & $\begin{array}{l}\text { Promotion of low emission agricultural } \\
\text { development }\end{array}$ &
\end{tabular}

Trees feature prominently in agricultural landscapes globally. Almost half of all agricultural lands maintain at least $10 \%$ tree cover (Zomer et al. 2014) (Table 6.1). Despite widespread distribution, tree outside forests (TOF) are an often neglected carbon pool and little information is available on carbon stocks in these systems or their carbon sequestration potential (de Foresta et al. 2013; Hairiah et al. 2011).

The ubiquity and use of trees in agricultural landscapes is significant for smallholder farmers' livelihoods and modifying local climate (van Noordwijk et al. 2014), but it also contributes to global climate change mitigation (Nair et al. 2009, 2010). Even when planted at low densities, the aggregate carbon accumulation in trees can help fight climate change because of the large spatial extent covered (Verchot et al. 2007; Zomer et al. 2014). Such trees are estimated to accumulate 3-15 $\mathrm{Mg} \mathrm{ha}^{-1}$ year $^{-1}$ in aboveground biomass alone (Nair et al. 2010), a non-trivial amount when compared to other carbon sinks such as soil. Simultaneously, trees diversify diets, reduce soil erosion, and expand market opportunities for smallholder farmers (Van Noordwijk et al. 2011). Thus, trees in agricultural landscapes offer opportunities to mitigate climate change and improve smallholder livelihoods (Kumar and Nair 2011). The synergy between climate adaptation and mitigation through trees in agricultural lands is now receiving explicit attention (Duguma et al. 2014).

Despite the significant advances in assessment methods, quantifying carbon stocks and fluxes at different spatial scale is still challenging. Although National Forest Inventories (NFIs) are supposed to provide such guidelines, they are well developed only in the Northern hemisphere. Most NFIs also do not include trees outside forests (TOF) and until recently TOF have been poorly defined (de Foresta et al. 2013; Baffetta et al. 2011). Hence sampling designs that can be consistently applied to both forests and TOF are lacking while ideally national biomass estimates should include carbon estimates of both forests and TOF. Most NFIs (except Sweden and Canada) do not include explicit TOF categories (de Foresta et al. 2013).

The dearth of consistent methodology and a new interest to integrate trees in farming systems in global biomass assessments (de Foresta et al. 2013) is catalyzing efforts to generate data on biomass and carbon specific for trees on farmland. This, however, comes with the challenge to rapidly develop and standardize methods for biomass assessment, obstacles in the forestry community has been grappling with for decades. Forest-based methodologies can be adapted for some applications. However, TOF present unique issues. To begin with, tree stands in agricultural 
landscapes typically show irregular shapes when compared to those in more dense forest stands. The geometry of tree stands on farmland is particularly plastic, sensitive to local environmental conditions (Harja et al. 2012), and human management (Dossa et al. 2007; Frank and Eduardo 2003). Tree management (pruning, coppicing, lopping, etc.) may violate assumptions of the available allometries, which were developed based on physiological relationships (e.g., mass and diameter at breast height (DBH)) observed in forests and plantations (Kuyah et al. 2012a). The impact of local edaphic conditions on tree growth combined with the diversity of uses and agroecological conditions complicates the construction of a coherent database to represent carbon and biomass estimation equations (BEMs) for farmland trees. The consequence is a scarcity of data and a fragmented understanding of the role trees on farms may play in climate and development discussions.

With more attention paid to farm forestry, agroforestry, and expansion of the agricultural frontier in many countries, quantification of biomass in trees in agricultural landscapes is receiving greater attention. There is a growing interest in the assessments of carbon stocks and sequestration for carbon monitoring and reporting needs, but also as a way to evaluate agricultural interventions (Thangata and Hildebrand 2012). In the following sections, we discuss general considerations of measurement accuracy, cost, and scale when quantifying and discuss the two predominant quantification approaches for biomass and carbon in trees on farms.

\subsection{Accuracy, Scale, and Cost}

Accurate estimates of changes in $\mathrm{C}$ stocks are required and uncertainties should be reduced as much as is practical (IPCC 2003). Yet, uncertainty depends strongly on scale and the costs of high accuracy plus high spatial resolution must be weighed against the benefits of farmer incentive schemes that need such information, as opposed to cheaper solutions that meet accuracy targets by spatial aggregation, e.g., to a $1 \mathrm{~km}^{2}$ scale (Lusiana et al. 2014). Methodological limitations and random as well as systematic errors associated with quantification of biomass of trees on farms guarantee uncertainties in estimates. A large degree of uncertainty exists in estimations of $\mathrm{C}$ stocks and fluxes at the local, regional, and global scale. Some of the uncertainty results from the lack of consensus on definitions, inconsistencies in methods, and assumptions leading to widely differing results even among similar studies (Sileshi 2014). These variations are mainly a result of lack of a common framework for sampling. Uncertainty in C estimation should be addressed to establish the reliability of estimates and provide a basis of confidence for decisionmaking, particularly where comparisons (e.g., with baseline results) are involved. Identified uncertainties can be quantified through statistical methods such as error propagation (Chave et al. 2004). Uncertainties in biomass quantification result from six primary sources in the quantification process: (1) the level of detail in the method used, (2) the complexities of the systems and landscapes being modeled, (3) sampling error, (4) measurement error, (5) model errors, and (6) the inconsistency in 
Table 6.2 Comparison of approaches and techniques in terms of scale, cost, and accuracy

\begin{tabular}{|c|c|c|c|c|}
\hline Approach & Scale & Cost & Accuracy & Uncertainty \\
\hline Destructive sampling & $\begin{array}{l}\text { Limited to } \\
\text { small area }\end{array}$ & Expensive & Most accurate & \\
\hline Allometry & $\begin{array}{l}\text { Allows } \\
\text { upscaling }\end{array}$ & $\begin{array}{l}\text { Cheap once } \\
\text { equations are } \\
\text { developed }\end{array}$ & $\begin{array}{l}\text { Relatively } \\
\text { accurate }\end{array}$ & \\
\hline Dendrochronology & $\begin{array}{l}\text { High } \\
\text { resolution at } \\
\text { tree level }\end{array}$ & $\begin{array}{l}\text { Cheap once } \\
\text { the lab } \\
\text { equipment } \\
\text { exists }\end{array}$ & $\begin{array}{l}\text { Very accurate } \\
\text { if individual } \\
\text { rings are easy } \\
\text { to read }\end{array}$ & $\begin{array}{l}\text { Missing rings, } \\
\text { wood anatomy, } \\
\text { wedging, etc. }\end{array}$ \\
\hline Remote sensing & $\begin{array}{l}\text { Variable } \\
\text { (high to low } \\
\text { resolution) }\end{array}$ & $\begin{array}{l}\text { High- } \\
\text { resolution } \\
\text { data are still } \\
\text { very } \\
\text { expensive }\end{array}$ & $\begin{array}{l}\text { Relatively } \\
\text { accurate } \\
\text { depending on } \\
\text { the indices of } \\
\text { method used }\end{array}$ & $\begin{array}{l}\text { For low resolution } \\
\text { there is blended } \\
\text { information that } \\
\text { reduce farm-level } \\
\text { assessment }\end{array}$ \\
\hline
\end{tabular}

estimating and reporting biomass components (Chave et al. 2004; IPCC 2003). Available biomass and carbon estimates for trees on farms vary considerably and associated measures of uncertainty in the estimates (e.g., standard errors and confidence intervals) are often not reported.

There is a potential mismatch between the scale at which measurements are made and the scale at which information is required for policy and programmatic development. Different methodologies allow quantification of carbon stocks at various spatial and temporal scales, ranging from plot to landscape scale and shorter and longer time horizons. Here again, the method used depends on the available funds and accuracy required. Field sampling methods destructive (i.e., harvesting trees, drying, and weighing biomass) or non-destructive (i.e., use of BEMs) are affordable and applicable for only a limited number of sites (Table 6.2). Remote sensing is practical and effective for mapping aboveground biomass in expansive remote areas, e.g., at regional scale.

The cost of carbon quantification depends on the method chosen, a choice that is determined by the scale of measurement and desired level of accuracy. The methods presented here vary in their degree of robustness, allowing for trade-offs between accuracy, cost, and practical viability for smallholder systems (Table 6.2). The key is to determine information that can be obtained at relatively low cost but still produces estimates within an acceptable level of accuracy. Destructive measurements are known to be costly in terms of resources, effort, and time, and are not permitted for rare or protected species. Modeling with BEMs is therefore an expedient way of estimating carbon both from field inventories or remote sensing. Obtaining field inventories is expensive, slow, and impractical in large areas. Ground-based measurements of tree diameters are therefore often combined with predictive models to estimate carbon stocks in small areas that can be upscaled. The costs on field inventories and analytical methods are greatly influenced by the sampling design used and the minimum number of measurement required for a particular method. For both modeling with BEMs and remote sensing, costs can be greatly reduced and 
efficiencies of labor and time achieved by adopting multipurpose sampling sites or procedures. For example, the sites could be designed to take measurements for carbon quantification, and also provide data for biodiversity analyses or assessment of vegetation and soil properties. An example is the Land Health Surveillance Framework, designed to cost-effectively enable measurement and monitoring of carbon in a given landscape over years (Vågen et al. 2010). Regarding the models, simple power-law models with DBH alone are less expensive to develop and use compared to parameter-rich models. This is because DBH measurements can be easily obtained at low cost compared to specialized equipment required for height or crown area measurements. Remote sensing can greatly reduce the time and cost of collecting data over large areas, particularly for highly variable, widely spaced, and hard-to-access areas (Wulder et al. 2008). However, remote sensing approaches such as airplane-mounted LiDAR instruments are still too costly and technically demanding. And while remote-sensing instruments can estimate proxies that can also be converted into biomass using statistical models; additional expenses will be incurred on field data for calibration/validation, which are also prone to errors. This is because there is no remote-sensing instrument that can presently measure tree carbon stocks directly (Gibbs et al. 2007).

\subsection{Quantification of Five Carbon Pools of Representative Plots}

Tree biomass can be estimated using direct (destructive) or indirect (non-destructive) approaches (Pearson et al. (2005) or GOFC-GOLD (2011) for methods, models, and parameters widely used). Direct methods require felling of trees and weighing the component parts. Destructive sampling provides the best data for building BEMs, generating inventory for estimating biomass, and providing requisite information for validating indirectly estimated biomass (Brown 1997; Gibbs et al. 2007). By contrast, indirect methods (e.g., BEMs and remote sensing) use readily measurable proxies, such as $\mathrm{DBH}$, crown area, or vegetation indices that are then converted into biomass based on statistical relationships established by destructive sampling (Brown 2002; Bar Massada et al. 2006). Unfortunately, most algorithms and regressions relating remotely sensed data to biomass increase precision, not accuracy. Therefore, it is important to make ground measurements to increase the accuracy of BEMs and remotely sensed data.

Cost considerations require that estimates of carbon stocks and stock changes on farms and landscapes be based on representative samples from land uses and covers and measurement of proxy variables rather than quantifying biomass on every farm or pixel and destructive sampling of trees, respectively. Indirect measures and statistical models only approximate biomass with a precision subject to the representativeness of the models to local conditions. That latter consideration is particularly salient for smallholder situations in tropical developing countries. Models have largely been constructed on data not collected in the tropics and little in Africa (Hofstad 2005; Henry et al. 2011) and even fewer data and BEMs are 
available for trees on farms. Applying equations to data with size range beyond the one that was used in building the equations can lead to high levels of bias and poor estimates of biomass. Biomass - and carbon - estimates by indirect methods will therefore always be inaccurate. Qualitatively, at least, the direct linkage between tree architecture, as modified by farm management, and fractal branching models that generate allometric equations suggests ways to make adjustments where major branches or parts of the crown are missing from trees (Hairiah et al. 2011; MacFarlane et al. 2014).

The cost and time of destructive measurement make it impractical for most uses. Therefore, this discussion focuses on indirect quantification methods. Indirect quantification of four IPCC identified biomass carbon pools (aboveground biomass, belowground biomass, deadwood, and litter) involves a series of steps (1) stratification/identification of the target areas, (2) measurement of proxies for biomass, (3) calculating biomass/carbon (4) scaling to whole-farms and landscapes (Fig. 6.1). This highlights the need to recognize two aspects to the uncertainty of carbon estimation: the first aspect is plot level-how good are measurements of biomass in the field? Do they account for belowground biomass, dead biomass, soil carbon, hollow trees, and smaller trees e.g., those $<10 \mathrm{~cm}$ diameter? How good are we at converting wood volumes into total aboveground biomass? The second aspect of uncertainty is converting plot-level measurements across space, either through modeling or with satellite data.

\section{Land cover change (activity data}

(1) Target \& identify Space ${ }^{*}$ Time* Use

(2) Plot-level observations \& proxies Dynamic Stand Models

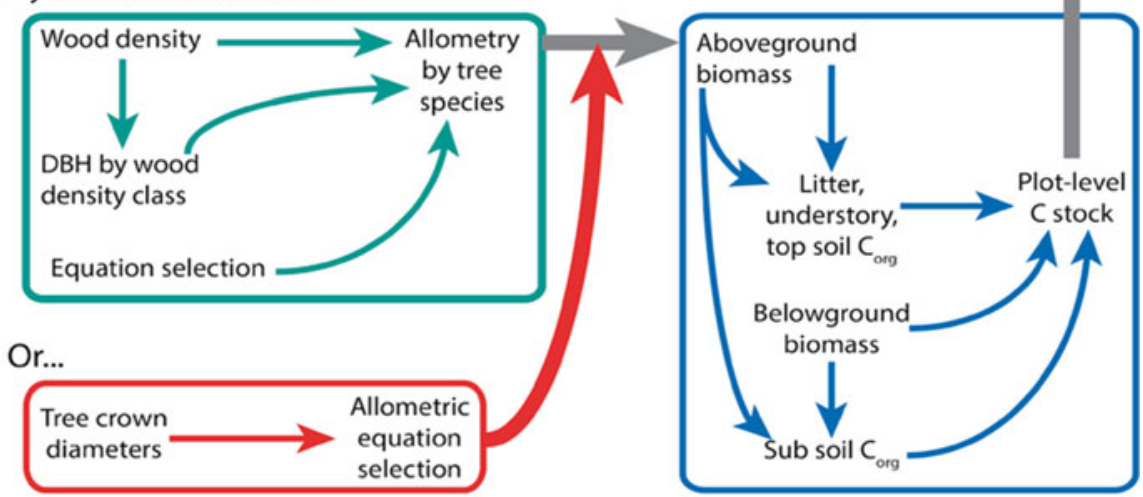

Fig. 6.1 Mixed-method approach to five-pool carbon estimates for farms and landscapes 


\subsubsection{Selecting Plots}

Quantification at farm and landscape scales requires extrapolation from data gathered from relatively small plots to larger areas. Extrapolation is necessary because it is prohibitively expensive to measure every tree on every farm or throughout the landscape. With stratification, we aim to quantify the biomass and carbon at a few representative locations and then use data on the frequency of their occurrence to calculate total biomass at larger spatial extents. It is therefore critically important that the sample is representative of the larger area and farm/ landscape features of interest and an estimate of the frequency of occurrence of the feature of interest is possible (Brown 1997). A stratified random sampling approach can be employed to guide sample selection ranging from remote sensing to household surveys. For building BEMs, a randomized pre-sample of trees can be generated from an inventory with respect to a stratified diameter class and trees for destructive sampling chosen through a blind selection without tree species association. For inventories, stratification by topographic features, management influence, and age classes are likely to produce more homogenous strata from which sample units could be selected. Age is essential particularly where lifecycle analysis is involved. In rotational plantations this is easy to implement, but in many land use systems derived from natural vegetation by selective retention of trees (e.g., shea or baobab trees in many savanna systems), regeneration pattern need to inform the sample selection. In systems with "internal regeneration," similar to natural forest with a gap renewal cycle, the age of the most frequent tree diameter class can be used to reconstruct a time-averaged carbon stock at the land use system level (Hairiah et al. 2011). We refer you to Chap. 2 of this manual and the references therein to determine an appropriate method for stratifying the sample. The remainder of this discussion assumes the availability of representative plots and knowledge of the relative distribution of different features or land use classes in the geographic space of interest.

\subsubsection{Measurements of Proxies for Tree Biomass}

Tree biomass is estimated from ground-based inventory data, remote sensing, or a combination of the two. Researchers and project developers tend to rely on BEMs, which calculate tree biomass based on easily measured dimensions based on the idea that standard relationships occur such as the diameter to mass or height to mass (West 2009) or root-to-shoot (Cairns et al. 1997; Mokany et al. 2006). Because of the variations in tree characteristics among ecological conditions, particularly in agricultural landscapes, and the need to account for biomass in all plant parts, it is ideal to use locally developed equations or develop BEMs at a local scale (Henry et al. 2011). Where local BEMs are not available, there are two other options. First, volume equation and inventory data arising from commercial 
interest valuing the stock of wood resources in forests may be available in many developing countries (Hofstad 2005; Henry et al. 2011). However, this approach provides data primarily on merchantable wood, leaving out components such as branches, twigs, and leaves, yet in some species these components constitute a significant amount, about $3 \%$, of the total aboveground biomass (Kuyah et al. 2013). The second option is to use the pantropical models (e.g., Chave et al. 2005). However, these are broadly derived, based on a large dataset and stratified by region or climatic conditions. The definition of climatic regimes is not intuitive and direct application of these models could give biased estimates if applied across the board, particularly in agricultural landscapes where trees face multiple stresses (Kuyah et al. 2012a; Sileshi 2014).

BEMs require the measurement of tree dimensions such as $\mathrm{DBH}$, basal area, height, or crown dimensions. Presuming measurements are conducted with care, accurate biomass estimates are best obtained by measurements of each parameter. However, certain measurements (e.g., height) are difficult to obtain accurately in the field by non-destructive methods and hence including this parameter in models may introduce error into the biomass estimates, by a mean of $16 \%$ (Hunter et al. 2013). Furthermore, complete datasets are in many cases not necessary to provide a reasonable estimate of biomass because inclusion of all parameters only moderately increases the accuracy of the total estimate. For example, inclusion of DBH alone provided an estimate within $1.5 \%$ of the actual biomass measured in an agricultural landscape of Western Kenya (Kuyah and Rosenstock in review), which agrees with most studies (Cole and Ewel 2006; Basuki et al. 2009; Bastien-Henri et al. 2010). Given the complexities and potential errors in measuring other parameters (i.e., difficult terrain or dense foliage when measuring height), the need for specialized tools (e.g., hypsometer or clinometer for height), or destructive measurements (e.g., wood density), the use of DBH alone appears cost-effective and robust for most purposes (Sileshi 2014).

At landscape scales, ground-based inventories are typically too resourceintensive to complete. Instead, crown area-which can be measured by remote sensing - is increasingly being tested for estimating aboveground biomass (Wulder et al. 2008; Rasmussen et al. 2011; Fig. 6.2). Two issues complicate widespread application of remote sensing and crown areas. First, crown area is not as strongly correlated with biomass as DBH. This may be particularly important for trees on farms that show irregular growth patterns due to variable environmental conditions (e.g., near red/far red light interception, availability of soil nutrients) or management by farmers (e.g., limb collection for firewood). For example, (Kuyah et al. 2012 b) show crown area measurements alone grossly misrepresent standing stocks of carbon, by about $20 \%$ relative to diameter estimates. It is therefore important to calibrate remotely sensed crown area estimates with field measured DBH to improve the accuracy of measurements. Second, remote sensing of crown areas for trees outside of forests requires high-resolution imagery to differentiate small features such as individual trees on farms. Typically, Quickbird images with sub-m resolution are best suited for this task but cost $\sim 15$ USD per $\mathrm{km}$. Without sufficient 


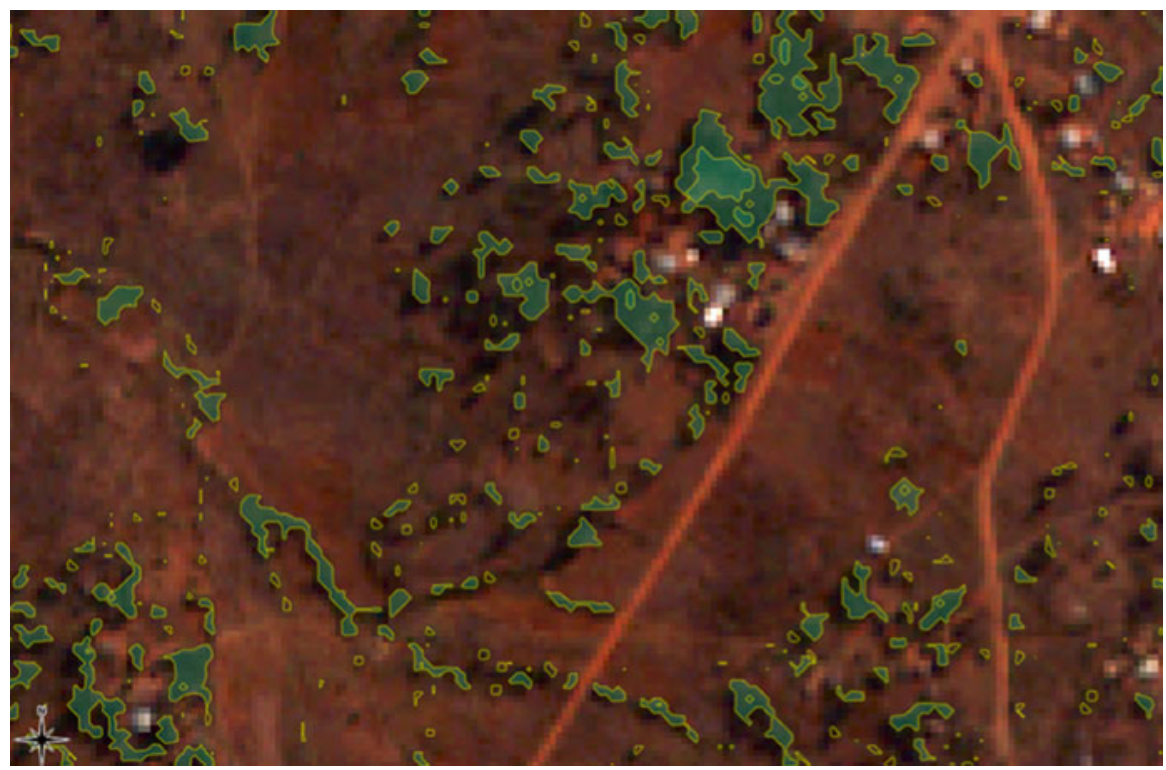

Fig. 6.2 Delineation of TOF crowns by remote sensing using sub-meter resolution Quickbird imagery (Gumbricht unpublished)

resolution, it is not possible to identify trees and may lead to underestimation of biomass. Unfortunately, the price of the satellite imagery increases in parallel with the resolution and the specialized skills necessary to process the imagery limits many applications of this technique outside of the research arena at this time. Despite the challenges, crown area allometry is likely the most promising approach to transform our ability to capture information on aboveground biomass stocks, potentially for relatively low total costs in the future (Gibbs et al. 2007; Wulder et al. 2008).

Field measurements and remote sensing generate estimates of aboveground biomass. Though most of the carbon in trees is contained in aboveground biomass, a significant fraction can be found in the four other major carbon pools: belowground biomass, litter, deadwood, and soils. Soil carbon is discussed in Chap. 7 (Saiz and Albrech this volume) and thus we restrict this brief discussion to the other three pools. For almost all applications, belowground biomass will be estimated by allometric relationships based on DBH or prescribed root-to-shoot ratios. We are quite skeptical of the accuracy of general root-to-shoot ratios for estimation of belowground biomass as the growth patterns are sensitive to water availability and may range from 10:1 in moist conditions versus 4:1 in arid conditions (IPCC 2003). Recent destructive experiments suggest that DBH may be a better predictor than root-to-shoot ratio for trees on farms but again require inventories to establish $\mathrm{DBH}$. Global studies show that belowground biomass (BG) is isometrically related to aboveground biomass (AG) (Hui et al. 2014; Cheng and Niklas 2007); i.e., $\mathrm{BG}=a(\mathrm{AG})$. If one can correctly 
estimate ' $a$ ', we believe estimating BG from AG using allometric method may be better than using shoot-to-root ratios.

Consideration of litter and deadwood deserve unique attention for trees on farm. Litter might be assumed to be in equilibrium with growth and thus ignored in biomass estimation especially on farmland. Deadwood might also be treated in the same way given most will be collected for firewood or in slash and burn agriculture, fire will consume most of it. A case can be made that the relative limited size of these pools justifies such treatment for most cases, especially when considering decadal timescales. In cases when litter and deadwood need to be estimated, measurements using small nested plots or an independent sampling design will be required. For litter, the information collected is total mass per unit area but for dead wood, depending on the size, one can measure total mass or estimate volume that can be used for mass calculation if wood density is known (Pearson et al. 2005, 2007).

\subsubsection{Calculating C Stocks and Fluxes}

Until now, we have been discussing the quantification of biomass stocks in a small plot area. Oftentimes, however, researchers and project developers are more interested in the change in carbon, accumulation or loss, with various practices or land use change. So here we consider methods to quantify rates of change in woody biomass.

\section{Time-Averaged Carbon Stock for Different Land Uses}

Carbon stocks in trees generally accumulate slowly over time. Often it is therefore most appropriate to analyze the changes over multiple years or decadal time scales. On longer time scales it is possible to analyze the average change (per annum or a given time interval) for the lifecycle of the land use or farming system (see Fig. 6.3, for example). Stock change accounting assesses the magnitude of change carbon stored between two or more ecosystems that share a reference state. This approach is desirable because it allows a researcher to substitute space for time, overcoming the challenges of returning to measure the same location/land use/trees twice. Researchers locate farming systems existing in the landscape that have already been transformed from other land use systems. Carbon stocks calculated from the different systems can then be compared to provide a relative estimate of changes over time. Characteristically, the changes are standardized to changes per year. This approach assumes that carbon stock changes results from land use change/ management and changes in carbon stocks are linear over the time period examined. This latter assumption negates the temporal dynamics of carbon. Yet, time averaged carbon stock presents a snapshot picture about the relative annual flux and cumulative impacts. 


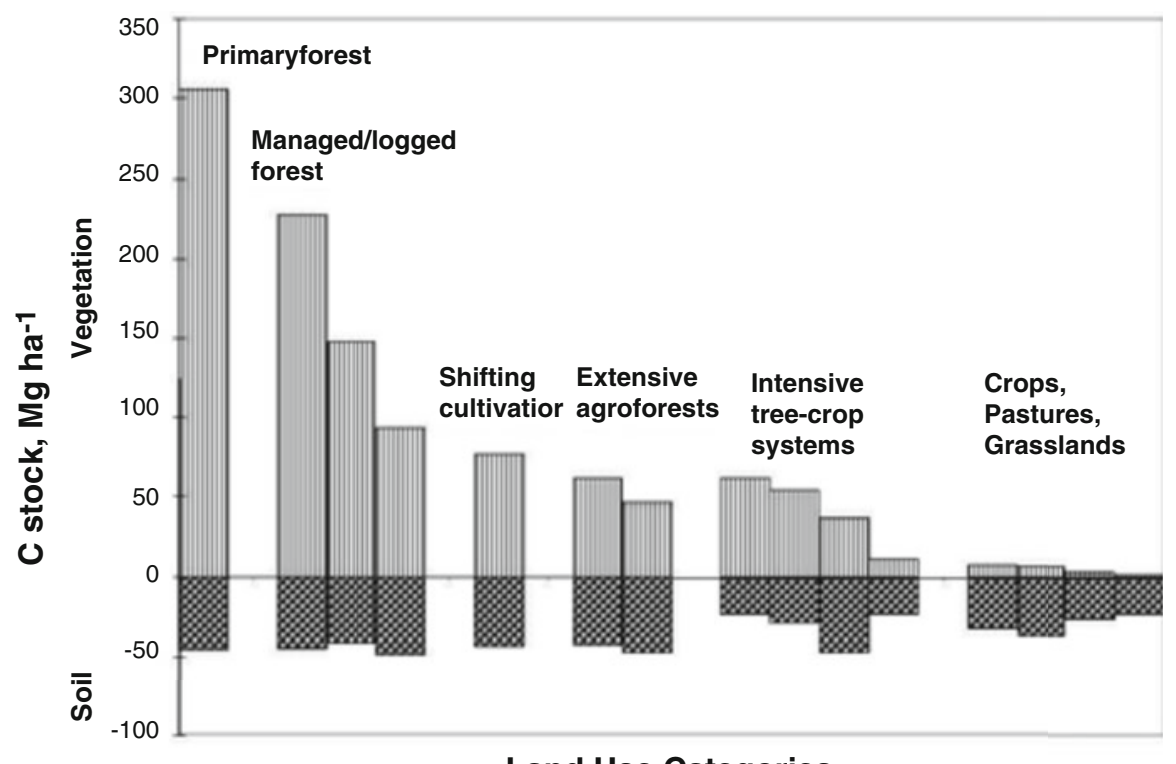

Fig. 6.3 Time-averaged aboveground carbon and total soil carbon $(0-20 \mathrm{~cm})$. Source: Hairiah et al. (2011)

\section{Annual Changes: Growth Rates, Dendrochronology, Repeated Measurements}

Though rarely quantified, examining annual changes in biomass carbon in trees on farm is important when calculating whole-farm GHG balances, that is, when calculating the global warming potential or global warming intensity of the system. Unfortunately, the growth rates of tropical tree species are only known for a small sample of commercially viable timber species and the remaining knowledge gap greatly limits the ability to map or model carbon stock changes. There are typically few options to gain information about annual stock changes in the absence of published growth rates: repeated measurements, biomass expansion factors (BEFs), and dendrochronology.

Repeated measurement of the same tree species is an option to create information on growth rates or annual changes in carbon stocks. Repeated measurements must be cautious to return precisely to the same tree/stand and the same measurement of the tree. Because repeated measurement relies on exact locations to document what can sometimes be small changes, this method is sensitive to observational and measurement errors as well as anomalies in growth patterns on the tree selected. Furthermore, repeated measurements can typically only be performed on a limited number of trees. Thus again, tree selection, to account for heterogeneity and minimize sampling artifacts, is critical. Though not without uncertainty, repeated measurement do provide a non-destructive approach to quantify short-term changes in carbon stocks. 
BEFs are another approach of using exiting stand volume data from previous forest studies to assess carbon density. BEF bundles two aspects, a conversion of volume to mass and an inclusion of ignored trees foliage, small branches not accounted in commercial volume assessment. The BEF is a conversion factor that calculates biomass based on traditional commercial volume data (Brown 1997).

The use of dendrochronology is an emerging field of application of tree ring for biomass assessment for individual tree growth. The method is based on the formation of annual rings in many tropical trees in areas with one distinct dry season. Often, this seasonality induces cambial dormancy of trees, particularly if these belong to deciduous species (Brienen and Zuidema 2005). Annual tree rings provide growth information for the entire life of trees and their analysis has become more popular in tropical forest regions over the past decades (Soliz-Gamboa et al. 2010). It is demonstrated that tree-ring studies is a powerful tool to develop highresolution and exactly dated proxies for biomass accumulation over time in individual trees (Mbow et al. 2013). In addition to annual increment of biomass, tree-ring analysis helps characterize climate-growth relationship between tree growth and rainfall in certain periods of the year and how this translates into tree productivity information that is central to carbon sequestration assessment (Mbow et al. 2013). Basically the use of such method implies the application of allometric models on diameter over bark on individual rings measured during the tree lifetime (Gebrekirstos et al. 2008). Important information can be collected using tree ring: (1) growth rate - average annual diameter increment-of-individual species to reconstruct long-term growth of trees and estimate productivity of trees; (2) age-diameter relationships which are required in carbon projections; (3) limiting factors of tree growth such as long time drought or severe fires.

\subsubsection{Scaling to Whole-Farms and Landscapes}

The final step involves aggregating the data on carbon stocks or stock changes into whole-farm and landscape-scale estimates. The precise scaling methods applied somewhat depend on the types of data collected and the equations used. However, scaling plot measurements will generally proceed in the following steps:

1. Land use/cover transition matrix in proportion for each zone by spatial analysis

2. Frequency of each zone by spatial analysis

3. Total area of the target area by spatial analysis (expressed in hectares)

4. Carbon stock of each system component calculated from the plot level measurements, allometric equations, and statistical analysis (expressed in $\mathrm{Mg} \mathrm{C}^{-1}$ )

5. Changes in the $\mathrm{C}$ stock for each transition by multiplying each cell in the matrix by the difference in the time-averaged $\mathrm{C}$ stock for each transition/conversion by the conversion factor (depending on plot size; expressed in $\mathrm{Mg} \mathrm{CO}_{2}$ equivalent $\mathrm{ha}^{-1}$ ) 
6. Annual changes in $\mathrm{C}$ stock for each transition by dividing changes in $\mathrm{C}$ stock by the length of the study period (expressed in $\mathrm{Mg} \mathrm{CO}_{2}$ equivalent ha ${ }^{-1}$ )

7. Total annual emission and total sequestration and net changes of $\mathrm{C}$ stock in the landscape (expressed in $\mathrm{Mg} \mathrm{CO}_{2}$ equivalent ha ${ }^{-1}$ )

Because the principal scaling approach relies on similarity-based relationships (e.g., allometric equations) that are scale invariant, the same steps are equally relevant for whole-farms or landscapes, irrespective of the spatial extent. Furthermore, since the results are expressed in $\mathrm{CO}_{2}$ equivalent ha ${ }^{-1}$ it is possible to integrate these measures with those from other GHG sources and sinks such as soil carbon or trace gas emissions from soils.

\subsection{Additional Sources of Information}

Because of the interest in forest inventories, there are countless sources of information available to help appropriately select and apply various techniques. Table 6.3 tabulates what we feel are the key sources of information, and links to specific protocols can be found on the website (http://www.samples.ccafs.cgiar. org/protocol/Biomass).

Table 6.3 Annotated key sources of information

Brown S (1997) Estimating Biomass and Biomass Change of Tropical Forests: a Primer. (FAO Forestry Paper-134). Food and Agriculture Organization of the United Nations (FAO), Rome, Italy

This report describes multiple methods for estimating biomass density, including one of the first comprehensive descriptions of methods for destructive biomass estimation. The report includes biomass estimates for different tropical countries based on forest type and climate. Supplementary tables report wood density for different tree species across tropical Asia, America, and Africa

West PW (2009) Tree and Forest Measurement. 2nd edition. Springer, Heidelberg, Germany

The primary audience for this book is undergraduate forestry students, practicing foresters, and landholders. As such, it introduces the techniques of tree and forest measurement with particular attention paid to non-destructive (allometric) approaches. This book provides a step-by-step description of how to measure trees as well as their component parts and then scale to the stand or population

One hundred years of tree-ring research in the tropics-a brief history and an outlook to future challenges. Dendrochronologia 20:217-231

This article describes the history of tree-ring analysis in the tropics. Tropical dendrochronology is hotly debated primarily because the consistent intra-annual temperatures of tropical systems do not produce the same tree-ring pattern we observe in temperate tree-rings. Worbes discusses the progress in and applications of tropical tree-ring research. One such application that we would like to highlight is the potential to use tree-rings to evaluate individual tree growth and thus track biomass accumulation through time 
Table 6.3 (continued)

Mbow C, Chhin S, Sambou B, Skole DL (2013) Potential of dendrochronology to assess annual rates of biomass productivity in savanna trees of West Africa. Dendrochronologia 31:41-51

This article describes the application of dendrochronology to assess biomass in individual savanna species in Southern Senegal. The materials and methods section provides a comprehensive description of the steps involved. Note that the destructive sampling was implemented in this study and may not be suitable for some situations

Gibbs HK, Brown S, Niles JO, Foley JA (2007) Monitoring and estimating tropical forest carbon stocks: making REDD a reality. Environ Res Lett 2:13

Using REDD (reductions in emissions from deforestation in developing countries) as a backdrop, this review paper discusses a range of methods available to estimate nationallevel forest carbon stocks using both ground-based and remotely sensed measurements of particular forest characteristics which can be converted into estimates of national carbon stocks using allometric relationships. This is the first article to report a complete set of national-level carbon stock estimates

Open Access This chapter is distributed under the terms of the Creative Commons Attribution 4.0 International License (http://creativecommons.org/licenses/by/4.0/), which permits use, duplication, adaptation, distribution and reproduction in any medium or format, as long as you give appropriate credit to the original author(s) and the source, a link is provided to the Creative Commons license and any changes made are indicated.

The images or other third party material in this chapter are included in the work's Creative Commons license, unless indicated otherwise in the credit line; if such material is not included in the work's Creative Commons license and the respective action is not permitted by statutory regulation, users will need to obtain permission from the license holder to duplicate, adapt or reproduce the material.

\section{References}

Baffetta F, Corona P, Fattorini L (2011) Assessing the attributes of scattered trees outside the forest by a multi-phase sampling strategy. Forestry 84(3):315-325

Bar Massada A, Carmel Y, Tzur GE, Grünzweig JM, Yakir D (2006) Assessment of temporal changes in aboveground forest tree biomass using aerial photographs and allometric equations. Can J Forest Res 36(10):2585-2594

Bastien-Henri S, Park A, Ashton M, Messier C (2010) Biomass distribution among tropical tree species grown under differing regional climates. For Ecol Manage 260:403-410

Basuki TM, van Laake PE, Skidmore AK, Hussin YA (2009) Allometric equations for estimating the above-ground biomass in tropical lowland Dipterocarp forests. For Ecol Manage 257(8):1684-1694

Brienen RJ, Zuidema PA (2005) Relating tree growth to rainfall in Bolivian rain forests: a test for six species using tree ring analysis. Oecologia 146(1):1-12

Brown S (1997) Estimating biomass and biomass change of tropical forests: a primer. In: FAO Forestry paper no. 134. Food and Agriculture Organization of the United Nations (FAO), Rome

Brown S (2002) Measuring carbon in forests: current status and future challenges. Environ Pollut 116:363-372

Cairns MA, Brown S, Helmer EH, Baumgardner GA (1997) Root biomass allocation in the world's upland forests. Oecologia 111:1-11

Chave J, Condit R, Aguilar S, Hernandez A, Lao S, Perez R (2004) Error propagation and scaling for tropical forest biomass estimates. Philos Trans R Soc Lond B Biol Sci 359:409-420

Chave J, Andalo C, Brown S, Cairns MA, Chambers JQ, Eamus D, Fölster H, Fromard F, Higuchi N, Kira T, Lescure J-P, Nelson BW, Ogawa H, Puig H, Riéra B, Yamakura T (2005) Tree 
allometry and improved estimation of carbon stocks and balance in tropical forests. Oecologia 145(1):87-99

Cheng DL, Niklas KJ (2007) Above- and below-ground biomass relationships across 1534 forested communities. Ann Bot 99(1):95-102

Cole T, Ewel J (2006) Allometric equations for four valuable tropical tree species. For Ecol Manage 229:351-360

de Foresta H, Somarriba E, Temu A, Boulanger D, Feuilly H, Gauthier M (2013) Towards the assessment of trees outside forests. In: Resources assessment working paper 183. Food and Agriculture Organization of the United Nations (FAO), Rome

Dossa EL, Fernandes ECM, Reid WS, Ezui K (2007) Above- and belowground biomass, nutrient and carbon stocks contrasting an open-grown and a shaded coffee plantation. Agrofor Syst 72(2):103-115

Duguma L, Minang PA, van Noordwijk M (2014) Climate change mitigation and adaptation in the land use sector: from complementarity to synergy. Environ Manage 54(3):420-432

Frank B, Eduardo S (2003) Biomass dynamics of Erythrina lanceolata as influenced by shoot pruning intensity in Costa Rica. Agrofor Syst 57:19-28

Gebrekirstos A, Mitlöhner R, Teketay D, Worbes M (2008) Climate-growth relationships of the dominant tree species from semi-arid savanna woodland in Ethiopia. Trees 22(5):631-641

Gibbs HK, Brown S, Niles JO, Foley JA (2007) Monitoring and estimating tropical forest carbon stocks: making REDD a reality. Environ Res Lett 2:1748-9326

GOFC-GOLD (2011) A sourcebook of methods and procedures for monitoring and reporting anthropogenic greenhouse gas emissions and removals caused by deforestation, gains and losses of carbon stocks in forests remaining forests, and forestation. GOFC-GOLD Report version COP17-1. GOFC-GOLD Project Office, Natural Resources Canada, Alberta

Hairiah K, Dewi S, Agus F, Velarde S, Ekadinata A, Rahayu S, van Noordwijk M (2011) Measuring carbon stocks across land use systems: a manual. World Agroforestry Centre (ICRAF), SEA Regional Office, Bogor

Harja D, Vincent G, Mulia R, Van Noordwijk M (2012) Tree shape plasticity in relation to crown exposure. Trees 26:1275-1285

Henry M, Picard N, Trotta C, Manlay RJ, Valentini R, Bernoux M, Saint-André L (2011) Estimating tree biomass of Sub-Saharan African forests: a review of available allometric equations. Silva Fennica 45(3B):477-569

Hofstad O (2005) Review of biomass and volume functions for individual trees and shrubs in Southeast Africa. J Trop For Sci 17:151-162

Hui D, Wang J, Shen W, Le X, Ganter P, Ren H (2014) Near isometric biomass partitioning in forest ecosystems of China. PLoS One 9(1), e86550

Hunter MO, Keller M, Victoria D, Morton DC (2013) Tree height and tropical forest biomass estimation. Biogeosciences 10(12):8385-8399

IPCC (2003) Good practice guidance for land use, land-use change and forestry. Intergovernmental Panel on Climate Change (IPCC) National Greenhouse Gas Inventories Programme. Institute for Global Environmental Strategies (IGES), Kanagawa

Kumar BM, Nair PKR (2011) Carbon sequestration potential of agroforestry systems: opportunities and challenges. In: Advances in agroforestry, vol 8. Springer, New York

Kuyah S, Dietz J, Muthuria C, Jamnadassa R, Mwangi P, Coe R, Neufeldt H (2012a) Allometric equations for estimating biomass in agricultural landscapes: I. Aboveground biomass. Agric Ecosyst Environ 158:216-224

Kuyah S, Muthuri C, Jamnadass R, Mwangi P, Neufeldt H, Dietz J (2012b) Crown area allometries for estimation of aboveground tree biomass in agricultural landscapes of Western Kenya. Agrofor Syst 86(2):267-277

Kuyah S, Dietz J, Muthuri C, van Noordwijk M, Neufeldt H (2013) Allometry and partitioning of above- and below-ground biomass in farmed eucalyptus species dominant in Western Kenyan agricultural landscapes. Biomass Bioenergy 55:276-284

Lusiana B, van Noordwijk M, Johana F, Galudra G, Suyanto S, Cadisch G (2014) Implication of uncertainty and scale in carbon emission estimates on locally appropriate designs to reduce emissions from deforestation and degradation (REDD+). Mitig Adapt Strat Glob Chang 19(6):757-772 
MacFarlane DW, Kuyah S, Mulia R, Dietz J, Muthuri C, van Noordwijk M (2014) Evaluating a non destructive method for calibrating tree biomass equations derived from tree branching architecture. Springer, Berlin

Mbow C, Chhin S, Sambou B, Skole DL (2013) Potential of dendrochronology to assess annual rates of biomass productivity in savanna trees of West Africa. Dendrochronologia 31:41-51

Mokany K, Raison RJ, Prokushkin AS (2006) Critical analysis of root shoot: ratios in terrestrial biomes. Glob Chang Biol 12:84-96

Nair PKR, Kumar BM, Nair VD (2009) Agroforestry as a strategy for carbon sequestration. J Plant Nutr Soil Sci 172:10-23

Nair PKR, Nair VD, Kumar BM, Showalter JM (2010) Carbon sequestration in agroforestry systems. In: Sparks DL, du Pont SH (eds) Advances in agronomy, vol 108, chap 5. Elsevier, Amsterdam

Pearson T, Walker S, Brown S (2005) Sourcebook for land use, land-use change and forestry projects. Winrock International. http://www.goldstandard.org/wp-content/uploads/2013/07/WinrockBioCarbon_Fund_Sourcebook-compressed.pdf. Accessed 29 Jan 2015

Pearson TRH, Brown S, Birdsey RA (2007) Measurement guidelines for the sequestration of forest carbon. In: General technical report NRS-18. USDA Forest Service. http://www.nrs.fs.fed.us/ pubs/gtr/gtr_nrs18.pdf. Accessed 29 Jan 2015

Rasmussen MO, Göttsche F-M, Diop D, Mbow C, Olesen F-S, Fensholt R, Sandholt I (2011) Tree survey and allometric models for tiger bush in northern Senegal and comparison with tree parameters derived from high resolution satellite data. Int J Appl Earth Obs Geoinf 13(4):517-527

Sileshi GW (2014) A critical review of forest biomass estimation models, common mistakes and corrective measures. For Ecol Manage 329:237-254

Soliz-Gamboa CC, Rozendaal DMA, Ceccantini G, Angyalossy V, Borg K, Zuidema PA (2010) Evaluating the annual nature of juvenile rings in Bolivian tropical rainforest trees. Trees 25(1):17-27

Thangata PH, Hildebrand PE (2012) Carbon stock and sequestration potential of agroforestry systems in smallholder agroecosystems of sub-Saharan Africa: mechanisms for 'reducing emissions from deforestation and forest degradation' (REDD+). Agric Ecosyst Environ 158:172-183

Vågen TG, Shepherd KD, Walsh MG, Winowiecki L, Desta LT, Tondoh JE (2010) AfSIS technical specifications: soil health surveillance. World Agroforestry Centre. http://worldagroforestry. org/sites/default/files/afsisSoilHealthTechSpecs_v1_smaller.pdf. Accessed 29 Jan 2015

Van Noordwijk M, Hoang MH, Neufeldt H, Öborn I, Yatich T (2011) How trees and people can co-adapt to climate change: reducing vulnerability in multifunctional landscapes. World Agroforestry Centre (ICRAF). http://www.worldagroforestry.org/sea/Publications/files/book/ BK0149-11.PDF. Accessed 29 Jan 2015

van Noordwijk M, Bayala J, Hairiah K, Lusiana B, Muthuri C, Khasanah N, Mulia R (2014) Agroforestry solutions for buffering climate variability and adapting to change. In: Fuhrer J, Gregory PJ (eds) Climate change impact and adaptation in agricultural systems. CABInternational, Wallingford, pp 216-232

Verchot LV, Noordwijk M, Kandji S, Tomich T, Ong C, Albrecht A, Mackensen J, Bantilan C, Anupama KV, Palm C (2007) Climate change: linking adaptation and mitigation through agroforestry. Mitig Adapt Strat Glob Chang 12(5):901-918

West PW (2009) Tree and forest measurement, 2nd edn. Springer, Heidelberg

Wulder MA, White JC, Fournier RA, Luther JE, Magnussen S (2008) Spatially explicit large area biomass estimation: three approaches using forest inventory and remotely sensed imagery in a GIS. Sensors 8:529-560

Zomer RJ, Trabucco A, Coe R, Place F, van Noordwijk M, Xu JC (2014) Trees on farms: an update and reanalysis of agroforestry's global extent and socio-ecological characteristics. Working paper 179. World Agroforestry Centre (ICRAF) SEA Regional Program, Bogor 